\title{
Hemodynamics and tissue oxygenation during balanced anesthesia with a high antinociceptive contribution: an observational study
}

\author{
Jaap Jan Vos ${ }^{1 *}$, Marieke Poterman ${ }^{1}$, Laura N Hannivoort ${ }^{1}$, Victor W Renardel De Lavalette ${ }^{2}$, Michel MRF Struys ${ }^{1}$,
} Thomas WL Scheeren ${ }^{1}$ and Alain F Kalmar ${ }^{1,3}$

\begin{abstract}
Background: In particular surgical conditions, a balanced anesthesia with a high-antinociceptive contribution is required. This may induce cardiovascular impairment and thus compromise tissue oxygenation. In this prospective observational study, we investigated the hemodynamic stability and tissue oxygen saturation $\left(\mathrm{StO}_{2}\right)$ in 40 patients with a high-antinociceptive general anesthesia, goal-directed fluid therapy, and norepinephrine. In addition, optimal surgical conditions and safe and fast emergence are pivotal parts of anesthetic management.

Methods: In high-antinociceptive propofol/remifentanil anesthesia with bispectral index (BIS) between 40 and 60, norepinephrine was administered to maintain mean arterial pressure (MAP) above $80 \%$ of individual baseline. Fluid was administered if the $\Delta$ plethysmographic waveform amplitude exceeded $10 \%$. Surgical and recovery conditions, hemodynamic responses, and tissue oxygenation were investigated.
\end{abstract}

Results: Mean (SD) $\mathrm{StO}_{2}$ at the left thenar eminence increased from 83 (6)\% before to 86 (4)\% 20 min after induction of anesthesia $(p<0.05)$. Cardiac index dropped from $3.0(0.7)$ to $2.1(0.4) \mathrm{L} \mathrm{min}^{-1}(p<0.05)$, MAP from 109 (16) to 83 (14) $\mathrm{mm} \mathrm{Hg}$, and heart rate from 73 (12) to 54 (8) bpm ( $p<0.05)$. Thirteen out of 40 patients received a fluid bolus. The median (range) norepinephrine administration rate was $0.05(0.0-0.10) \mathrm{\mu g} \mathrm{kg}^{-1} \mathrm{~min}^{-1}$. After complete akinesia in all patients during surgery, a median (IQR) extubation time of 311 (253-386) s was observed.

Conclusions: This high-antinociceptive balanced anesthesia with goal-directed fluid and vasopressor therapy adequately preserved $\mathrm{StO}_{2}$ and hemodynamic homeostasis.

Trial registration: ISRCTN20153044

Keywords: Propofol, Remifentanil, Cardiac output, Fluid therapy, Balanced anesthesia, Tissue oxygenation, Norepinephrine

\section{Background}

Induction to a level of anesthesia adequate to tolerate laryngoscopy requires a combination of hypnotics and analgesics that may induce significant hemodynamic suppression attributed to peripheral vasodilatation, loss of venous tone causing reduction in preload and venous return, and to a lesser extent, a decreased myocardial contractility. After intubation, the sudden decrease in nociceptive stimuli often results in hypotension

\footnotetext{
*Correspondence: j.j.vos@umcg.nl

'Department of Anesthesiology, University of Groningen, University Medical Center Groningen, Groningen, The Netherlands

Full list of author information is available at the end of the article
}

and frequently requires administration of vasoactive medication if surgical stimulation remains absent for a significant time. These agents may however jeopardize hemodynamic stability and tissue oxygenation [1]. Yet, particular surgical interventions require a sustained high level of analgesia, although only occasional but intense nociceptive stimuli occur in between long periods of low stimulation. In these fluctuating surgical conditions, maintaining a stable anesthesia (which can, among other variables, be reflected by a BIS-value between 40 and 60) may be challenging in view of the fluctuating noxious stimuli. A reliable method to assess the quality 
of analgesia level is complete tolerance to laryngoscopy, which reflects an equal tolerance to typical surgical stimuli [2].

In addition, many of these surgical interventions have only limited analgesic needs once the procedure is finished making the pharmacological profile of remifentanil suitable for this purpose.

In most surgical conditions, a sound approach to compensate for alternating stimuli would be decreasing the level of analgesia. However, in many procedures where continuous muscle relaxants are undesirable and complete akinesia is nonetheless required, an alternative strategy must be pursued while addressing obvious concerns regarding hemodynamic disturbances and awareness [3].

Furthermore, a safe and fast emergence from anesthesia with avoidance of sudden increases in intra-ocular or middle-ear pressure during extubation [4,5], a full cooperative patient soon after surgery and a concise recovery period is often a pivotal part of the anesthetic management.

Whilst all these desired anesthetic requirements are being addressed, adequate tissue perfusion and oxygenation must be preserved. Only relying on the arterial blood pressure to maintain adequate tissue oxygenation is insufficient, yet most advanced hemodynamic monitoring devices are moderately to highly invasive and are associated with rare but serious complications limiting their value in many patients [6-8]. In the surgical settings described above (with a substantial percentage of day-case surgery), non-invasive monitoring (i.e., providing sufficient information without the risk of inducing complications) is mandatory. The Inspectra ${ }^{\circ}$ device (Hutchinson Technology, Hutchinson, KS, USA) can be used to continuously monitor the tissue oxygen saturation $\left(\mathrm{StO}_{2}\right)$ non-invasively on the thenar muscle using near-infrared spectroscopy (NIRS) [9] while the Nexfin ${ }^{\circ}$ monitor (Edwards Lifesciences, Irvine, CA, USA) permits non-invasive measurement of various hemodynamic variables in a beat-to-beat fashion [9-14]. The aim of this observational study was to describe the adequacy of tissue oxygenation and hemodynamic stability together with the quality of the surgical conditions and emergence from anesthesia in a tightly-specified balanced anesthesia with a high-antinociceptive contribution combined with a goal-directed fluid and vasopressor therapy.

\section{Methods}

After the Institutional Ethics Committee approval (Ref: 2012.052, Ethics Committee, University Medical Center Groningen, Groningen, The Netherlands), 40 consecutive adult patients scheduled for a day-case surgery under general anesthesia were recorded and written informed consent was asked for data-analysis. The study was registered at Current Controlled Clinical Trials (ISRCTN20153044).

\section{Anesthetic management}

One gram of Paracetamol was administered orally prior to admission to the OR. Intravenous access was secured using an 18G IV catheter in a left large forearm vein, and a continuous background infusion of crystalloids was started at $90 \mathrm{ml} \mathrm{hr}^{-1}$. Anesthesia was induced with remifentanil $\left(1 \mu \mathrm{g} \mathrm{kg}^{-1}\right)$, propofol $\left(1-3 \mathrm{mg} \mathrm{kg}^{-1}\right)$, and cisatracurium $\left(0.1 \mathrm{mg} \mathrm{kg}^{-1}\right)$.

In patients with preexisting cardiovascular comorbidities such as hypertension, reported peripheral or coronary artery disease in whom post-induction hypotensiondefined as a $20 \%$ decrease $[15,16]$ in baseline mean arterial pressure (MAP) - can be expected, a norepinephrine $(10 \mu \mathrm{g})$ single bolus was co-administered prophylactically.

After tracheal intubation, the lungs were ventilated in a volume controlled mode with a tidal volume of $8 \mathrm{ml} \mathrm{kg}$ lean body weight with a mixture of $\mathrm{O}_{2} /$ air $\left(\mathrm{F}_{\mathrm{i}} \mathrm{O}_{2} 0.4\right)$ and $5 \mathrm{~cm} \mathrm{H}_{2} \mathrm{O}$ PEEP. The respiratory rate was adjusted to keep an end-tidal $\mathrm{CO}_{2}$ pressure between 4.5 and $5.5 \mathrm{kPa}$.

Anesthesia was maintained with propofol $\left(4 \mathrm{mg} \mathrm{kg}^{-1} \mathrm{hr}^{-1}\right)$ and remifentanil $\left(0.25 \mu \mathrm{g} \mathrm{kg}^{-1} \mathrm{~min}^{-1}\right)$ and adequate doses of hypnotics and analgesics to tolerate laryngoscopy $[2,17]$ and to keep BIS between 40 and 60. If necessary, these doses could be increased in $30 \%$ steps. In addition, norepinephrine was infused as required to keep MAP above $80 \%$ of individual baseline (preoperative ambulatory pressure) $[15,16]$.

The level of respiratory induced variation in the pulse oximetry plethysmographic waveform amplitude $(\triangle \mathrm{POP})$ [18] was assessed 2 min after intubation; if it was found to be above $10 \%$, hypovolemia was assumed and a fluid bolus of $500 \mathrm{ml}$ colloid solution (Voluven', Fresenius, Bad Homburg, Germany) was administered.

Administration of propofol, remifentanil, and norepinephrine was stopped simultaneously when the surgical procedure was finished. The trachea was extubated under continuous suction only after the patients were consciously responding and after they deeply inhaled upon verbal command. The extubation time, defined as the time between cessation of the syringe pumps and the moment of extubation, was recorded together with the incidence of any coughing reflex upon extubation. Any patient movement during the procedure was recorded. Two hours after recovery from anesthesia, patients were explicitly asked for any (adverse) experience in the perianesthetic period.

\section{Monitoring}

In addition to standard monitoring, a bispectral index (BIS) sensor (Aspect Medical Systems, Norwood, MA, USA) was placed on the forehead $[19,20]$. The non-invasive Inspectra $^{\circ}$ device (Model 650, Hutchinson Technology, Hutchinson, KA, USA) measures the peripheral $\mathrm{StO}_{2}$ 
based on near-infrared spectrometry [9]. This device emits near-infrared light (600-800 $\mathrm{nm}$ ) to the tissue, which then undergoes changes in its spectrum, mostly depending on the degree of microvascular hemoglobin saturation. The probe can be placed on different anatomical locations; but it was placed on the left thenar eminence because of the limited fat-layer with little inter-individual variation [9]. The anesthetist was blinded for $\mathrm{StO}_{2}$ readings. The Nexfin ${ }^{\bullet}$ monitor (model 1) is a non-invasive advanced hemodynamic monitoring device with a working principle that is based on the volume clamp method using a photoplethysmograph and an inflatable cuff placed around the intermediate phalanx [21]. This device provides continuous calculation of arterial blood pressure, systemic vascular resistance, stroke volume, cardiac output (CO), and heart rate in a beat-to-beat fashion [10-14].

\section{Data registration and analysis}

The Philips MP70 anesthesia monitor (Philips, Eindhoven, Netherlands) was connected to a PC, and all patient data were recorded at a 1-s interval using Rugloop II datamanager software (Demed, Temse, Belgium). The time and dose of all administered drugs were recorded in the Rugloop system, together with any noteworthy events or patient responses. The following variables were recorded: $\mathrm{SpO}_{2}, \mathrm{StO}_{2}$, heart rate (HR), MAP, CO, Cardiac Index (CI), and BIS. The electronic data were imported into Microsoft Excel $2010^{\circ}$ (Microsoft, Redmond, WA, USA). After a graphical representation, a visual inspection of the data plots was performed to correct obvious atypical values caused by artifacts.

\section{Statistics}

All statistics were performed using Microsoft Excel $2010^{\circ}$ and PASW Statistics 18 (SPSS Inc, Chicago, IL, USA). Data were expressed as mean (SD), median (range), or number of patients (\%). Normality of continuous variables was assessed using the Kolmogorov-Smirnov test. Continuous repetitive data before induction, and at 20 and $60 \mathrm{~min}$ thereafter were compared using the paired $t$ test. Statistical significance level was set at $p<0.05$.

\section{Results}

A total of 40 consecutive patients were screened for eligibility and subsequently enrolled.

Forty consecutive patients scheduled for ophthalmic surgery under general anesthesia were recorded. Mean (SD) age was 64 (13) years, weight was 82 (14) kg, and height was $176(10) \mathrm{cm}$. There were 11, 23, and 6 patients of ASA classifications I, II, and III respectively. The median (range) duration of surgery was $73(30-184) \mathrm{min}$. No use of neuromuscular reversal agents was necessary. In two patients $(5 \%)$, an increase in the dosage of both propofol and remifentanil was required, whereas in one patient (2.5\%), only the dosage of propofol was increased.

Overall, the median (range) administration rate of norepinephrine was $0.05(0.00-0.10) \mu \mathrm{g} \mathrm{kg}^{-1} \mathrm{~min}^{-1}$. Thirty-two patients were given a prophylactic dose of $10 \mu \mathrm{g}$ norepinephrine at induction of anesthesia. Twenty-one patients were administered $0.05 \mu \mathrm{g} \mathrm{kg}^{-1} \mathrm{~min}^{-1}$ norepinephrine continuously, while in eight patients, this administration rate could be either reduced to $0.025 \mu \mathrm{g} \mathrm{kg}^{-1} \mathrm{~min}^{-1}$ or stopped. In two patients, the administration rate was increased to $0.075 \mu \mathrm{g} \mathrm{kg} \mathrm{gin}^{-1}$ and in one patient to $0.1 \mu \mathrm{g} \mathrm{kg}^{-1} \mathrm{~min}^{-1}$. Eight patients did not receive norepinephrine at all. Thirteen of the forty patients showed a $\triangle$ POP above $10 \%$ and were subsequently administered $500 \mathrm{ml}$ fluid.

Evolution of hemodynamic variables and bispectral index Figure $1 A, B, C, D, E$ shows the time course of both the individual and mean values (in bold) of the investigated variables for the first $90 \mathrm{~min}$. All data were synchronized at the start of induction of anesthesia. Figure 2 shows the mean values of all the investigated variables with a time interval of $1 \mathrm{~min}$.

MAP decreased significantly from 109 (16) to 83 (14) $\mathrm{mmHg}(p<0.05)$ after induction and remained stable afterwards. No inadvertent severe hypertension following prophylactic norepinephrine administration was observed at induction (Figure 1A). Heart rate also decreased upon induction of anesthesia from 73 (12) to 54 (8) bpm $(p<0.05)$ but remained stable afterwards (56 (9) $\mathrm{bpm}$ at $60 \mathrm{~min}$; non-significant vs. $20 \mathrm{~min})$. After an initial drop in cardiac index from $3.0(0.7) \mathrm{L} \mathrm{min}^{-1} \mathrm{~m}^{-2}$ at induction to $2.1(0.4) \mathrm{L} \mathrm{min}^{-1} \mathrm{~m}^{-2}$ at $20 \mathrm{~min}$ thereafter $(p<0.05)$, it gradually increased again to $2.4(0.4) \mathrm{L}$ min $\mathrm{m}^{-2}(p<0.05)$ at $60 \mathrm{~min}$. $\mathrm{StO}_{2}$ increased significantly within minutes after induction of anesthesia from 83 (6)\% before induction to 86 (4)\% at $20 \mathrm{~min}$ after induction of anesthesia $(p<0.05)$ to remain stable thereafter (87 (4)\% at 60 min after induction of anesthesia). The mean (SD) BIS value dropped from 95 (4) before induction to $44(9)$ after $20 \mathrm{~min}(p<0.05)$ and remained stable afterwards (mean BIS 44 (10) at $60 \mathrm{~min}$ ).

Figure 3 shows the changes in $\mathrm{CI}$ and $\mathrm{StO}_{2}$ from preanesthesia level to $20 \mathrm{~min}$ after induction in a scatterplot. Accordingly, a majority of patients have an increased $\mathrm{StO}_{2}$ despite decreased CI. There was no significant correlation between $\mathrm{CI}$ and $\mathrm{StO}_{2}$ values.

\section{Quality of surgical conditions}

Complete akinesia was realized in all patients in the period between induction of anesthesia and the end of surgery, while no additional relaxant was administered after intubation and $90 \%$ of the cases lasted longer than 45 min. No neuromuscular reversal agents were needed. 


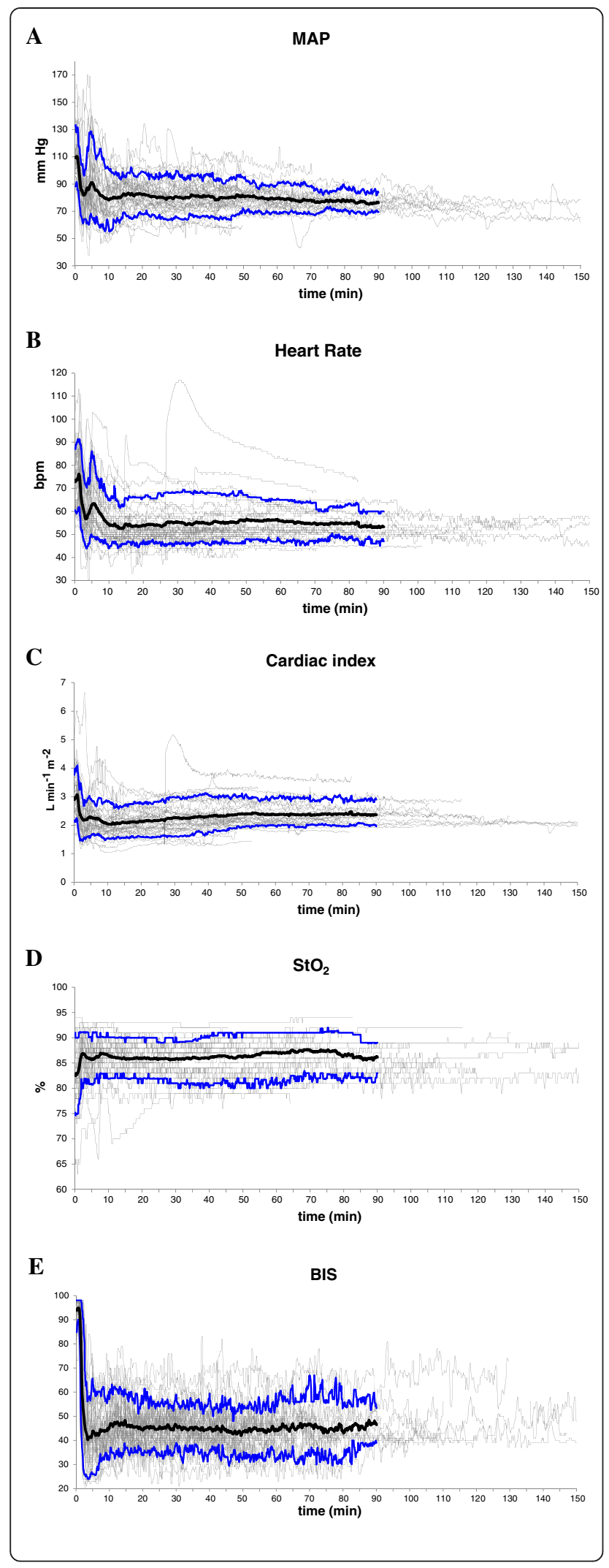

Figure 1 Evolution of individual values (grey), mean value (black), and 10th and 90th percentile (blue). (A) Mean arterial pressure. (B) Heart rate. (C) Cardiac index. (D) Tissue oxygen saturation. (E) Bispectral index. Values are shown from the moment of induction of anesthesia up to the end of the procedure. Mean and percentiles are shown for the first 90 minutes.

The median (range) extubation time was 311 (72-600) s with an interquartile range of 253-386 s. None of the patients exhibited a coughing reflex upon extubation and none of the patients reported awareness or unpleasant experiences in the peri-anesthetic period upon explicit questioning $2 \mathrm{~h}$ after extubation.

\section{Discussion}

In this prospective study in 40 patients, we have shown that during a high-antinociceptive balanced general anesthesia with propofol and remifentanil, goal-directed fluid administration and vasopressor support with norepinephrine results in a hemodynamically stable procedure with preservation of tissue oxygen saturation. This study performed in patients undergoing surgery with minimal noxious stimuli most of the time allows optimal quantification of the diverse effects of the anesthetic management with minimal interference of the surgical procedure. The combination of propofol/remifentanil, reported to provide an optimal depth of anesthesia, was also selected to produce a level of analgesia providing tolerance to laryngoscopy in $>80 \%$ of cases (ED80) [2]. However, administration of analgesics to reach this high probability of tolerance to laryngoscopy requires a corresponding decrease in hypnotics in order to prevent excessive depth of anesthesia. Low BIS values (less than 30-40) are indicative of burst suppression [22], which is not considered a physiological EEG pattern, and has been correlated with poor outcome $[16,23]$. An appropriate decrease in propofol level is adequately reflected in a fitting mean (SD) BIS value of 44. This high level of antinociception proved to provide excellent analgesic and hypnotic conditions during surgery while also preventing intra- or postoperative events that might lead to increases in intra-ocular pressure or pharyngeal reflexes albeit allowing quick extubation with eventless recovery.

\section{Critique of the methods}

Firstly, the current study was neither designed as a randomized controlled trial nor has there been a control group. The study was nonetheless aimed to elucidate the effects of a balanced high-antinociceptive general anesthesia on tissue oxygen saturation in a clinical setting, for which an observational study would be the most appropriate.

Secondly, the current study was performed solely in patients undergoing ophthalmic surgery and therefore 


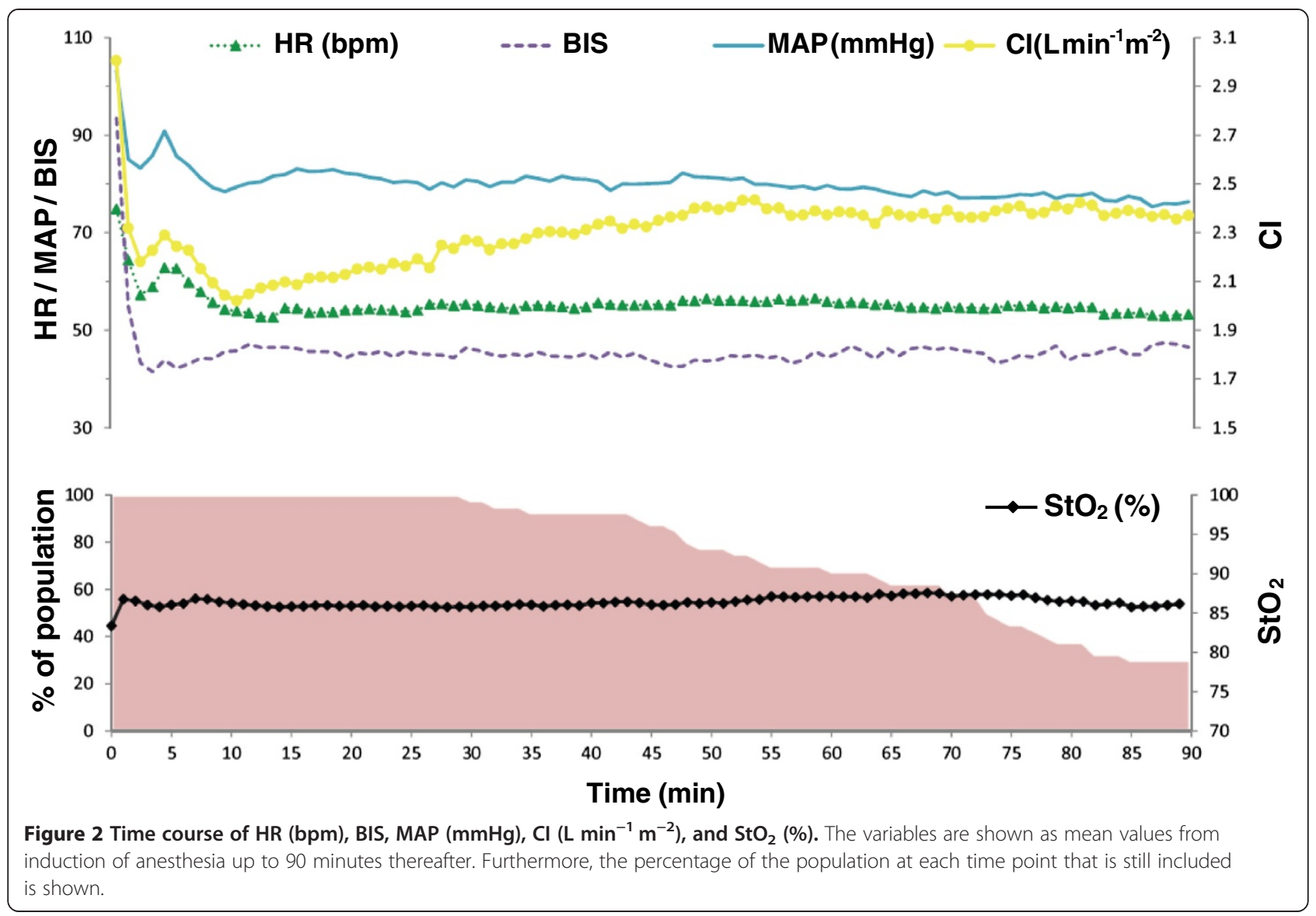

we cannot draw firm conclusions on the question whether this anesthetic regimen would be applicable during other types of surgery. Nevertheless, we speculate that in other surgical procedures associated with intermittent painful stimuli but requiring absolute akinesia (e.g., rigid laryngoscopy) and subsequently requiring rapid recovery with a fully responsive and cooperative patient, the investigated high-antinociceptive balanced anesthesia might be of particular use. Further studies should address this issue.

While invasive measurements are conventionally preferred to continuously assess hemodynamic variables, we used the non-invasive Nexfin ${ }^{\bullet}$ device, for which accuracy and precision of MAP measurements were recently shown, to meet the Association for the Advancement of Medical Instrumentation criteria in patients undergoing thoracic surgery [24] and also, were shown to be not inferior to noninvasive cuff manometric measurement of MAP in hemodynamically stable patients under general anesthesia [10]. This device also measures $\mathrm{CO}$ with a percentage error (PE) between $23 \%$ and $26 \%$ compared to thermodilution derived $\mathrm{CO}$ measurements as reported for patients who are awake before and after coronary artery bypass surgery [25]. Another study [14], investigating the influence of phenylephrine infusion on $\mathrm{Nexfin}^{\circ} \mathrm{CO}$ measurements, found a high concordance $(94 \%)$ between phenylephrine-induced changes in $\mathrm{CO}$ measured by Nexfin ${ }^{\circ}$ and by esophageal Doppler. The PE found in this study was however relatively high with a PE of $33 \%$ before and $42.5 \%$ after phenylephrine infusion, suggesting a reduced accuracy after vasopressor administration. Yet, Nexfin ${ }^{\circ} \mathrm{CO}$ accuracy still requires further investigation in patients under general anesthesia and in situations such as hemodynamic instability or during infusion of (other) vasoactive drugs, e.g., norepinephrine. Nevertheless, this device allows continuous and non-invasive monitoring of blood pressure and flow without adding additional risk to the patient. Additionally, recent technologic advances have also allowed the ability to calculate dynamic preload variables, such as pulse pressure and stroke volume variation, in an automated continuous noninvasive fashion [18], yet with a reported [26] higher accuracy in assessing fluid responsiveness than clinical $\triangle \mathrm{POP}$ assessment, as was performed in the current study.

Finally, the site and technology to determine tissue oxygenation may have some limitations. In particular, myoglobin can have relatively high oxygen saturation even in case of tissue hypoperfusion and decreased oxygenation, and it could be a major contributor to the readings obtained. As a consequence, there is a debate on which site should be preferred to accurately measure 


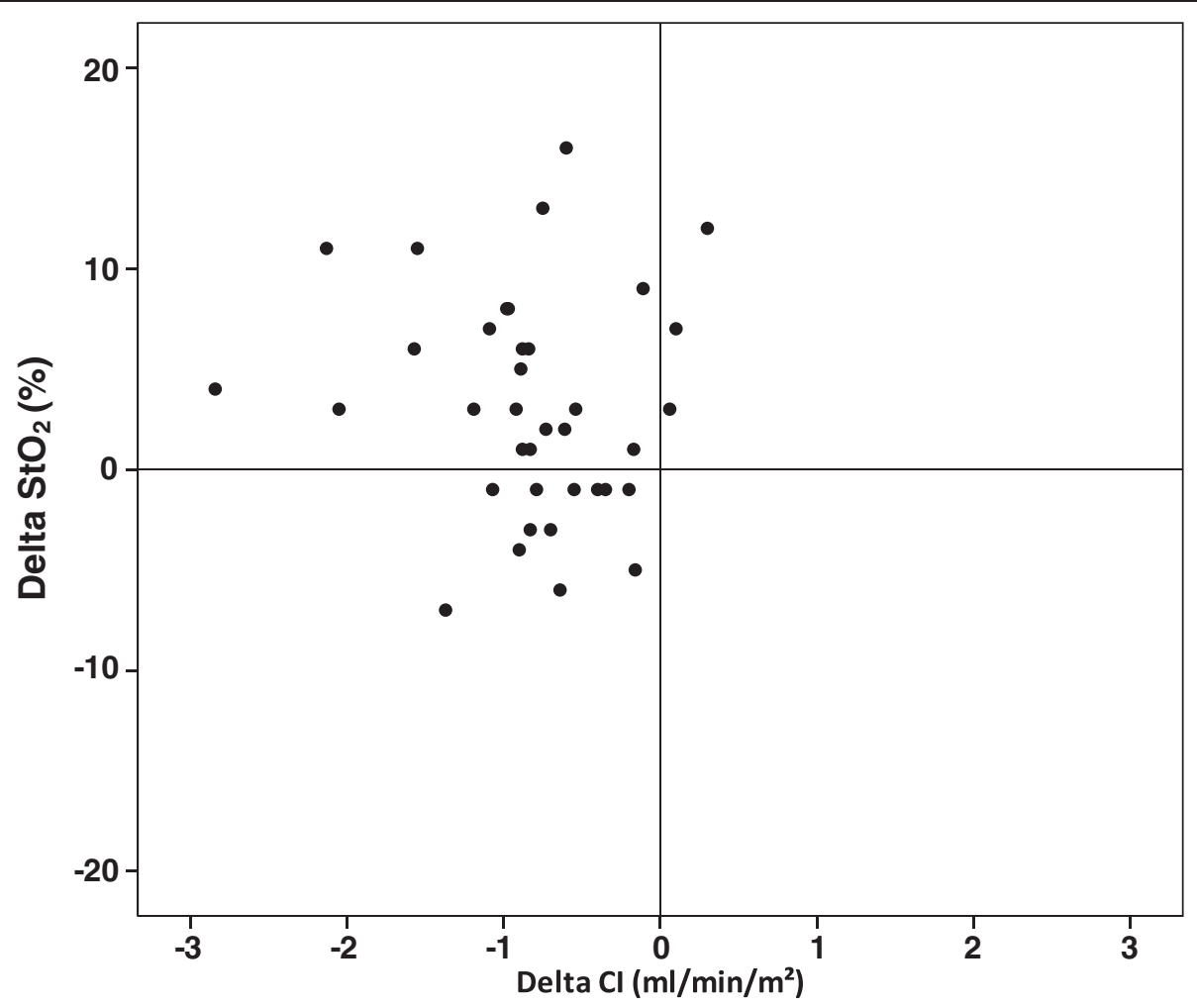

Figure 3 The change in $\mathrm{Cl}$ and $\mathrm{StO}_{2}$ between pre-anesthesia level and 20 min after induction.

$\mathrm{StO}_{2}$ [27]. However, the systematic increase in $\mathrm{StO}_{2}$ relative to baseline we observed in the current study convincingly demonstrates a favorable mixed effect of the anesthesia on global $\mathrm{StO}_{2}$.

\section{Quality of surgical conditions and emergence from anesthesia}

In many surgical situations, a balanced high-antinociceptive general anesthesia is indicated, and a combination of propofol/remifentanil is appreciated. Based on the pharmacodynamic principle of equivalent anesthetic depth at different ratios of hypnotic/opiate, the chosen combination of propofol/remifentanil induced a sufficient level of anesthesia-reflected in normal BIS values between 40-60-although with a relatively higher contribution of remifentanil [2], resulting in a higher tolerance for sudden noxious stimuli. The favorable pharmacokinetic profile of this remifentanil/propofol combination resulted in a short median time to extubation-defined as the time interval between stopping the syringe pumps and the moment of extubation-of $311 \mathrm{~s}$ with low variability, together with optimal recurrence conditions: the fast elimination of propofol with still adequate analgesia at extubation results at the moment of endotracheal extubation in a complete suppression of potentially deleterious coughing reflexes and appropriate cooperation in all patients.

\section{Hemodynamics and tissue oxygenation}

Anesthesia was induced with propofol, $1-3 \mathrm{mg} \mathrm{kg}^{-1}$, and remifentanil, $1 \mu \mathrm{g} \mathrm{kg}^{-1}$ : a combination that can acutely decrease vascular tonus, heart rate, and cardiac output with resulting relative hypotension [28], which was also observed in the current study (Figure 2).

Firstly, in order to preserve cardiac preload, 13/40 patients were administered fluid as the $\triangle \mathrm{POP}$ value was $>10 \%$, indicating fluid responsiveness, i.e., cardiac preload dependency.

Secondly, the decrease in CI following anesthesia induction is largely attributable to the (remifentanil-induced) decrease in heart rate (Figure 2), while stroke volume itself was relatively maintained probably because of both increased cardiac filling time and anesthesia-induced peripheral vasodilation and reduced cardiac afterload. The decrease in blood pressure after induction of anesthesia was anticipated with a single bolus of $10 \mu \mathrm{g}$ norepinephrine at induction and a concomitantly started background infusion of norepinephrine. Most importantly, the administration of norepinephrine at the reported dose, in combination with goal-directed fluid optimization, was able to preserve a MAP at $80 \%$ of individual baseline values with a benign decrease in $\mathrm{CO}$ and without exerting adverse effects on $\mathrm{StO}_{2}$.

A major concern of combining potent hypnotics/ analgetics with a vasopressor is a negative end-effect 
on cardiac output and ultimately on tissue oxygenation. Therefore, a rational dosing is essential to obtain the desired intubation conditions and surgical stability, with optimal preservation of hemodynamic homeostasis. The stable BIS value within the recommended range reflects an adequate and reliable depth of hypnosis and demonstrates that a strong antinociceptive effect can be safely obtained if combined with an adequately adapted administration of propofol. Secondary, while the slight increase in tissue oxygenation is reassuring, a significant decrease in $\mathrm{CI}$ between awake and post-induction state demonstrates the potent hemodynamic effects of induction of even a balanced anesthesia. This decrease in CI is mainly based on a decrease in systemic resistance and heart rate and a preserved stroke volume. The resulting decrease in cardiac oxygen consumption, combined with a preserved peripheral tissue oxygenation, suggests that a CI decrease to this extent can be considered acceptable for induction of anesthesia. The subsequent increase in $\mathrm{CI}$ and stable MAP and $\mathrm{StO}_{2}$ demonstrates that the moderate continuous doses of vasopressor are sufficient and appropriate to sustain hemodynamic stability during guaranteed optimal surgical conditions. However, the potent effects of the vasopressors must be reckoned with and must be considered in respect to other cardiovascular comorbidities. In addition, a more subtle administration of hypnotics/ analgetics, such as based on TCI models, may be more appropriate in vulnerable patients.

While this desired MAP may appear relatively high for some clinicians, several reports $[15,16]$ acknowledge the utmost importance of a preserved MAP up this value to prevent adverse outcome. Importantly, care must be taken that potent vasopressors like norepinephrine are administered with respect to appropriate safety measures, such as the preferable use of a dedicated line and avoidance of inadvertent boluses.

For patients under general anesthesia, $\mathrm{StO}_{2}$ values around $80 \%$ are considered within the normal range [29]. The increase in $\mathrm{StO}_{2}$ to $86(4) \%$ in our study was most probably caused by peripheral vasodilation due to the combination of propofol and remifentanil. This finding is in contrast to a previous study in which no differences in $\mathrm{StO}_{2}$ were found before and after induction of anesthesia [29]. The use of sufentanil in this previous study may account for this difference. Nevertheless, $\mathrm{StO}_{2}$ is believed to be a flow-dependent variable [9]. Furthermore, it has been shown to be independent of MAP and remained almost constant at different levels of MAP [30]. It has however not yet been investigated whether thenar $\mathrm{StO}_{2}$ values also correlate with oxygen saturation of tissues of vital importance (e.g., heart, brain, kidney, liver). Subsequently, although the data show favorable values of thenar $\mathrm{StO}_{2}$, indicating adequate peripheral tissue oxygenation (at least in the range of MAP and CI values observed), 'macro' hemodynamic values such as $\mathrm{CI}$, heart rate, and MAP are of great importance for assuring patient safety.

\section{Conclusions}

A high-antinociceptive balanced anesthesia with goaldirected fluid and norepinephrine administration preserved tissue oxygen saturation while other hemodynamic variables remained within a clinically acceptable range. Furthermore, this approach provided reliable surgical conditions, complete akinesia, and swift postoperative recovery.

\section{Competing interests}

The authors declare that they have no competing interests.

\section{Authors' contributions}

JJV was involved in the patient inclusion, data recording, data analysis and interpretation, and manuscript writing. MP participated in the data analysis and manuscript writing. LNH participated in the data analysis, pharmacologic modeling, data interpretation, and manuscript writing. WWRDL was involved in the patient inclusion and manuscript writing. MMRFS and TWLS participated in the data interpretation and manuscript writing. AFK was involved in the patient inclusion and patient care, data recording, data analysis and interpretation, and manuscript writing. All authors read and approved the final manuscript.

\section{Acknowledgements}

Support for this study was solely provided by departmental and institutional funding.

\section{Author details}

${ }^{1}$ Department of Anesthesiology, University of Groningen, University Medical Center Groningen, Groningen, The Netherlands. ${ }^{2}$ Department of Ophthalmology, University of Groningen, University Medical Center Groningen, Groningen, The Netherlands. ${ }^{3}$ Department of Anaesthesiology and Intensive care medicine, Maria Middelares hospital, Ghent, Belgium.

Received: 11 June 2014 Accepted: 8 October 2014

Published: 30 October 2014

\section{References}

1. Meng L, Cannesson M, Alexander BS, Yu Z, Kain ZN, Cerussi AE, Tromberg BJ, Mantulin WW: Effect of phenylephrine and ephedrine bolus treatment on cerebral oxygenation in anaesthetized patients. Br J Anaesth 2011, 107:209-217.

2. Bouillon TW, Bruhn J, Radulescu L, Andresen C, Shafer TJ, Cohane C, Shafe SL: Pharmacodynamic interaction between propofol and remifentanil regarding hypnosis, tolerance of laryngoscopy, bispectral index, and electroencephalographic approximate entropy. Anesthesiology 2004, 100:1353-1372.

3. Sandin RH, Enlund G, Samuelsson P, Lennmarken C: Awareness during anaesthesia: a prospective case study. Lancet 2000, 355:707-711.

4. Cunningham AJ, Barry P: Intraocular pressure-physiology and implications for anaesthetic management. Can Anaesth Soc J 1986, 33:195-208.

5. Murphy DF: Anesthesia and intraocular pressure. Anesth Analg 1985, 64:520-530

6. Leone M, Blidi S, Antonini F, Meyssignac B, Bordon S, Garcin F, Charvet A, Blasco V, Albanese J, Martin C: Oxygen tissue saturation is lower in nonsurvivors than in survivors after early resuscitation of septic shock. Anesthesiology 2009, 111:366-371

7. Brzezinski M, Luisetti T, London MJ: Radial artery cannulation: a comprehensive review of recent anatomic and physiologic investigations. Anesth Analg 2009, 109:1763-1781.

8. Cohn SM: Near-infrared spectroscopy: potential clinical benefits in surgery. J Am Coll Surg 2007, 205:322-332.

9. Scheeren TW, Schober P, Schwarte LA: Monitoring tissue oxygenation by near infrared spectroscopy (NIRS): background and current applications. J Clin Monit Comput 2012, 26:279-287. 
10. Vos JJ, Poterman M, Mooyaart EAQ, Weening M, Struys MMRF, Scheeren TWL, Kalmar AF: Comparison of continuous non-invasive finger arterial pressure monitoring with conventional intermittent automated arm arterial pressure measurement in patients under general anaesthesia. Br J Anaesth 2014, 113:67-74

11. Eeftinck Schattenkerk DW, van Lieshout JJ, van den Meiracker $A H$ Wesseling KR, Blanc S, Wieling W, van Montfrans GA, Settels JJ, Wesseling $\mathrm{KH}$, Westerhof BE: Nexfin noninvasive continuous blood pressure validated against riva-Rocci/Korotkoff. Am J Hypertens 2009, 22:378-383.

12. Hofhuizen CM, Lemson J, Hemelaar AE, Settels JJ, Schraa O, Singh SK, van der Hoeven JG, Scheffer GJ: Continuous non-invasive finger arterial pressure monitoring reflects intra-arterial pressure changes in children undergoing cardiac surgery. Br J Anaesth 2010, 105:493-500.

13. Nowak RM, Sen A, Garcia AJ, Wilkie H, Yang JJ, Nowak MR, Moyer ML: Noninvasive continuous or intermittent blood pressure and heart rate patient monitoring in the ED. Am J Emerg Med 2011, 29:782-789.

14. Chen G, Meng L, Alexander B, Tran NP, Kain ZN, Cannesson M: Comparison of noninvasive cardiac output measurements using the nexfin monitoring device and the esophageal doppler. J Clin Anesth 2012, 24:275-283.

15. Sessler DI, Sigl JC, Kelley SD, Chamoun NG, Manberg PJ, Saager L, Kurz A, Greenwald S: Hospital stay and mortality are increased in patients having a "triple low" of low blood pressure, low bispectral index, and low minimum alveolar concentration of volatile anesthesia. Anesthesiology 2012, 116:1195-1203.

16. Monk TG, Saini V, Weldon BC, Sigl JC: Anesthetic management and one-year mortality after noncardiac surgery. Anesth Analg 2005, 100:4-10.

17. Bouillon TW: Hypnotic and opioid anesthetic drug interactions on the CNS, focus on response surface modeling. Handb Exp Pharmacol 2008, 182:471-487.

18. Vos JJ, Kalmar AF, Struys MMRF, Wietasch JKG, Hendriks HGD, Scheeren TWL: Comparison of arterial pressure and plethysmographic waveform based dynamic preload variables in assessing fluid responsiveness and dynamic arterial tone in patients undergoing major hepatic resection. Br J Anaesth 2013, 110:940-946.

19. Gan TJ, Glass PS, Windsor A, Payne F, Rosow C, Sebel P, Manberg P: Bispectral index monitoring allows faster emergence and improved recovery from propofol, alfentanil, and nitrous oxide anesthesia. BIS utility study group. Anesthesiology 1997, 87:808-815.

20. Kearse LA Jr, Manberg P, Chamoun N, Chamoun N, de Bros F, Zaslavsky A Bispectral analysis of the electroencephalogram correlates with patient movement to skin incision during propofol/nitrous oxide anesthesia. Anesthesiology 1994, 81:1365-1370.

21. Imholz BP, Wieling W, van Montfrans GA, Wesseling KH: Fifteen years experience with finger arterial pressure monitoring: assessment of the technology. Cardiovasc Res 1998, 38:605-616.

22. Besch G, Liu N, Samain E, Pericard C, Boichut N, Mercier M, Chazot T, Pili FS: Occurrence of and risk factors for electroencephalogram burst suppression during propofol-remifentanil anaesthesia. Br J Anaesth 2011, 107:749-756

23. Leslie K, Myles PS, Forbes A, Chan MT: The effect of bispectral index monitoring on long-term survival in the B-aware trial. Anesth Analg 2010, 110:816-822.

24. Martina JR, Westerhof BE, van Goudoever J, de Beaumont EM, Truijen J, Kim YS, Immink RV, Jobsis DA, Hollmann MW, Lahpor JR, de Mol BA, van Lieshout JJ: Noninvasive continuous arterial blood pressure monitoring with nexfin(R). Anesthesiology 2012, 116:1092-1103.

25. Broch O, Renner J, Gruenewald M, Meybohm P, Schottler J, Caliebe A, Steinfath M, Malbrain M, Bein B: A comparison of the nexfin(R) and transcardiopulmonary thermodilution to estimate cardiac output during coronary artery surgery. Anaesthesia 2012, 67:377-383.

26. Rinehart J, Islam T, Boud R, Nguyen A, Alexander B, Canales C, Cannesson $M$ : Visual estimation of pulse pressure variation is not reliable: a randomized simulation study. J Clin Monit Comput 2012, 26:191-196.

27. Van Beest PA, Scheeren TW: Tissue oxygen saturation as a goal, but when and where should we measure it? J Clin Monit Comput 2013, 27:211-213.

28. Habib AS, Parker JL, Maguire AM, Rowbotham DJ, Thompson JP: Effects of remifentanil and alfentanil on the cardiovascular responses to induction of anaesthesia and tracheal intubation in the elderly. Br J Anaesth 2002, 88:430-433.
29. Bernet C, Desebbe O, Bordon S, Lacroix C, Rosamel P, Farhat F, Lehot JJ, Cannesson M: The impact of induction of general anesthesia and a vascular occlusion test on tissue oxygen saturation derived parameters in high-risk surgical patients. J Clin Monit Comput 2011, 25:237-244.

30. Spruit RJ, Schwarte LA, Hakenberg OW, Scheeren TW: Association of intraoperative tissue oxygenation with suspected risk factors for tissue hypoxia. J Clin Monit Comput 2013, 27:541-550.

doi:10.1186/2047-0525-3-9

Cite this article as: Vos et al:: Hemodynamics and tissue oxygenation during balanced anesthesia with a high antinociceptive contribution: an observational study. Perioperative Medicine 2014 3:9.

\section{Submit your next manuscript to BioMed Central and take full advantage of:}

- Convenient online submission

- Thorough peer review

- No space constraints or color figure charges

- Immediate publication on acceptance

- Inclusion in PubMed, CAS, Scopus and Google Scholar

- Research which is freely available for redistribution

Submit your manuscript at www.biomedcentral.com/submit
C) Biomed Central 